Supporting Information for

\title{
Synthesis and Biological Properties of Porphyrin-Containing Polymeric Micelles with Different Sizes
}

Jialiang Zhang, Zhengkui Zhang, Bo Yu, Chen Wang, Wei Wu*, Xiqun Jiang*

MOE Key Laboratory of High Performance Polymer Materials and Technology, Department of Polymer Science \& Engineering, College of Chemistry \& Chemical Engineering, and Jiangsu Key Laboratory for Nanotechnology, Nanjing University, Nanjing, 210093, P. R. China

* To whom correspondence should be addressed

Email: wuwei@nju.edu.cn,jiangx@nju.edu.cn 


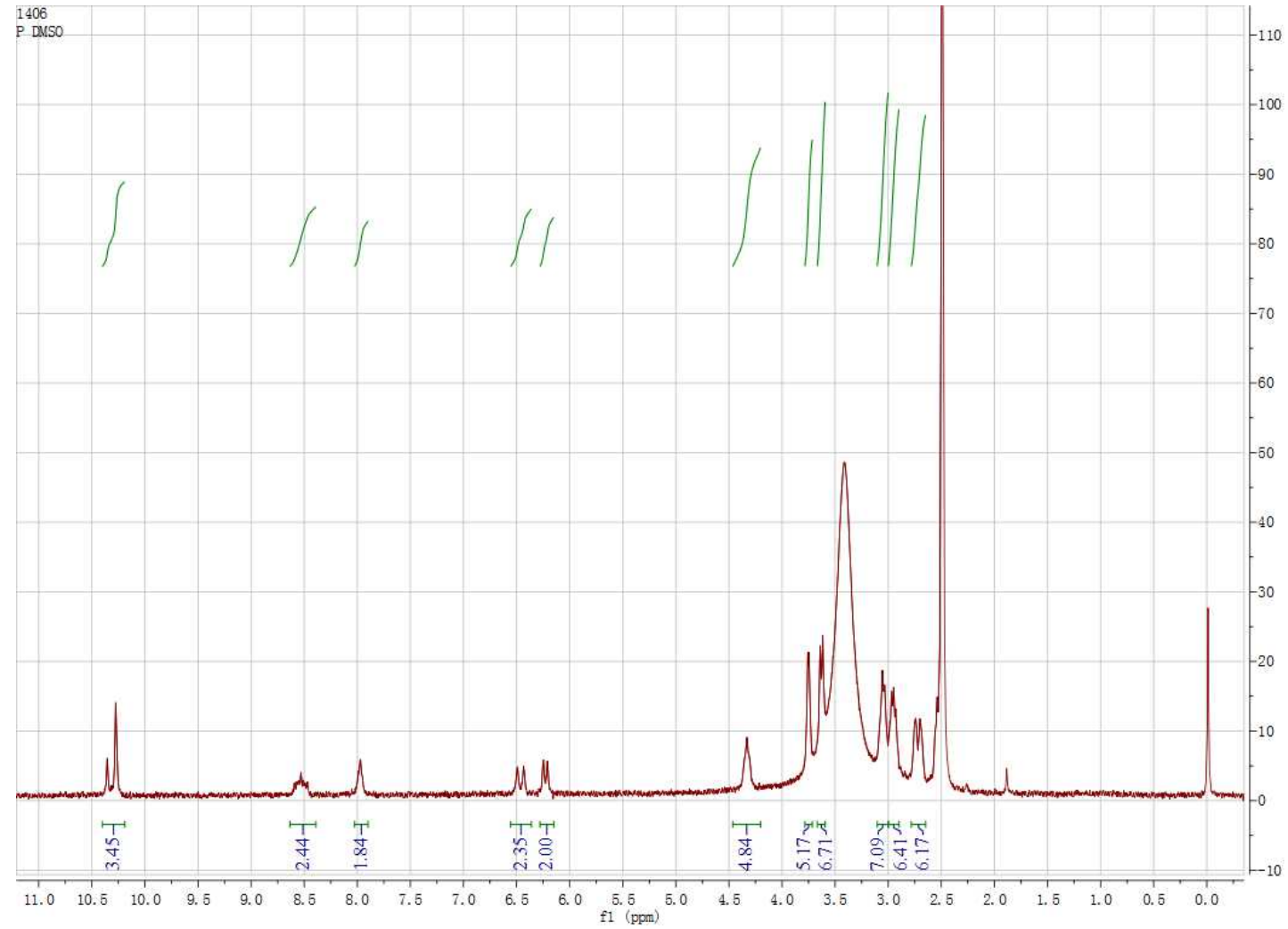

Figure S1. ${ }^{1} \mathrm{H}$ NMR spectra of PP-(TEG) 2 in $\mathrm{d}_{6}$-DMSO. 


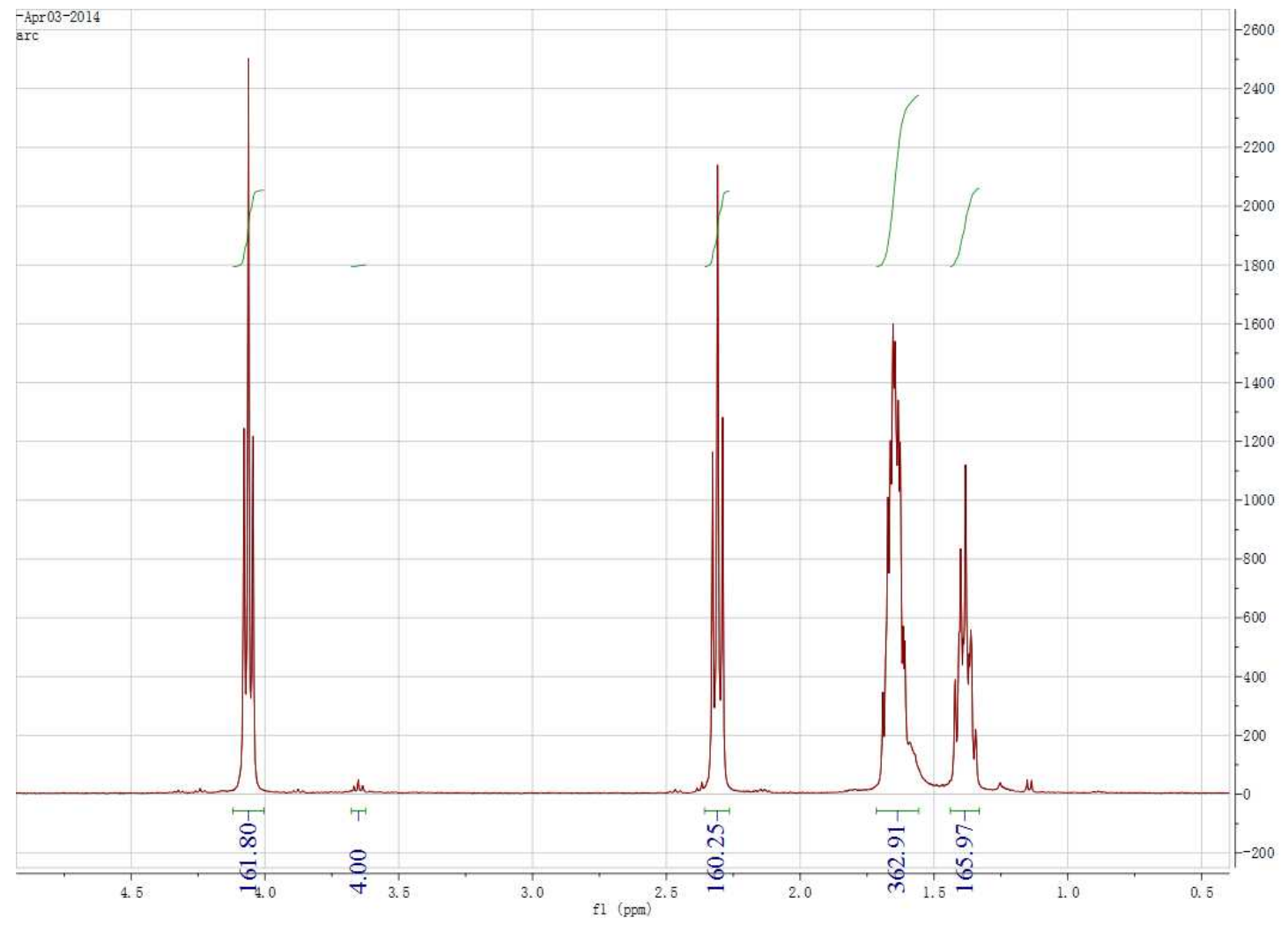

Figure S2. ${ }^{1} \mathrm{H}$ NMR spectra of PP-PCL in $\mathrm{CDCl}_{3}$. 


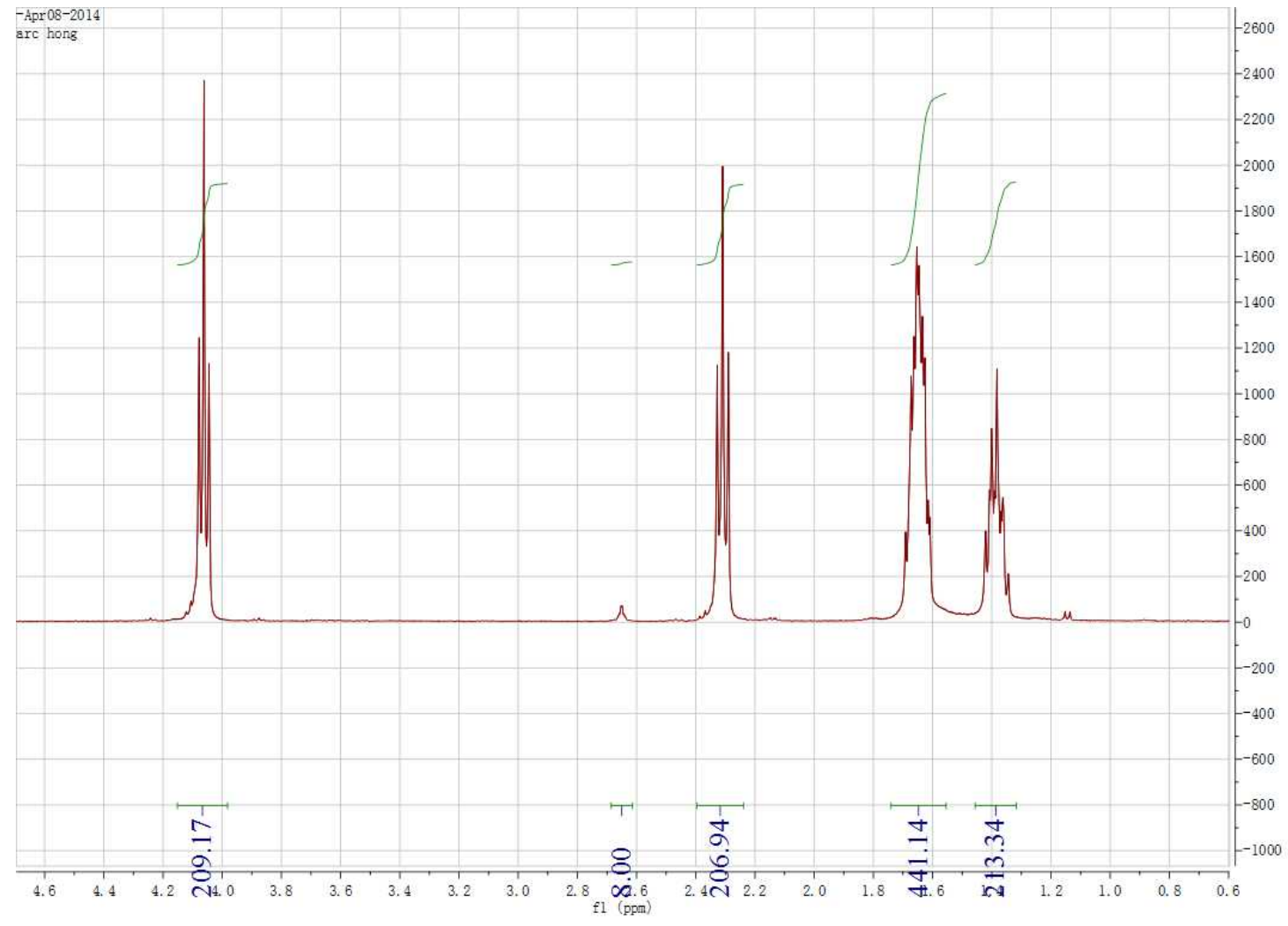

Figure S3. ${ }^{1} \mathrm{H}$ NMR spectra of PP-PCL-COOH in $\mathrm{CDCl}_{3}$. 


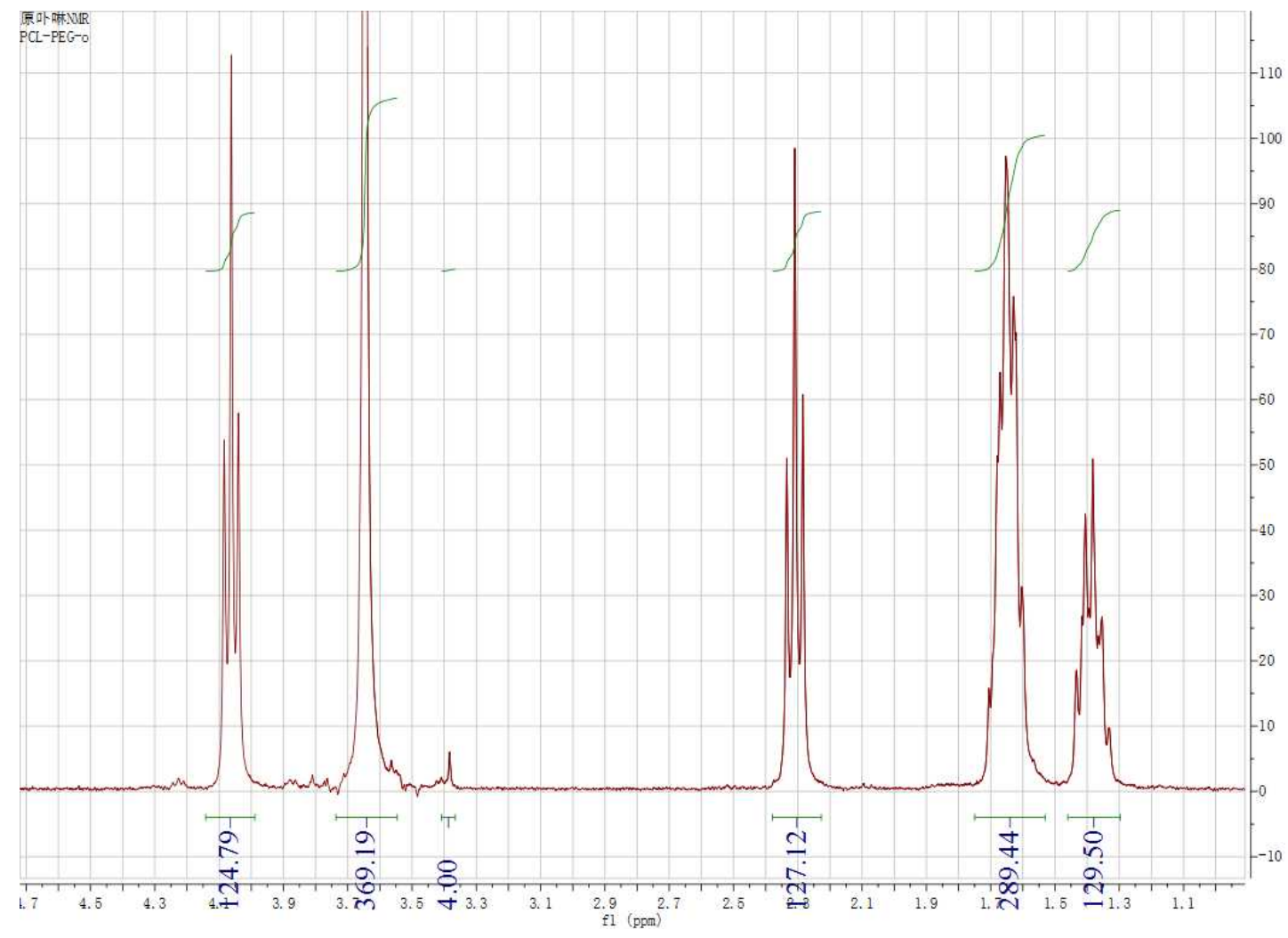

Figure S4. ${ }^{1} \mathrm{H}$ NMR spectra of PP-PCL-PEG in $\mathrm{CDCl}_{3}$. 


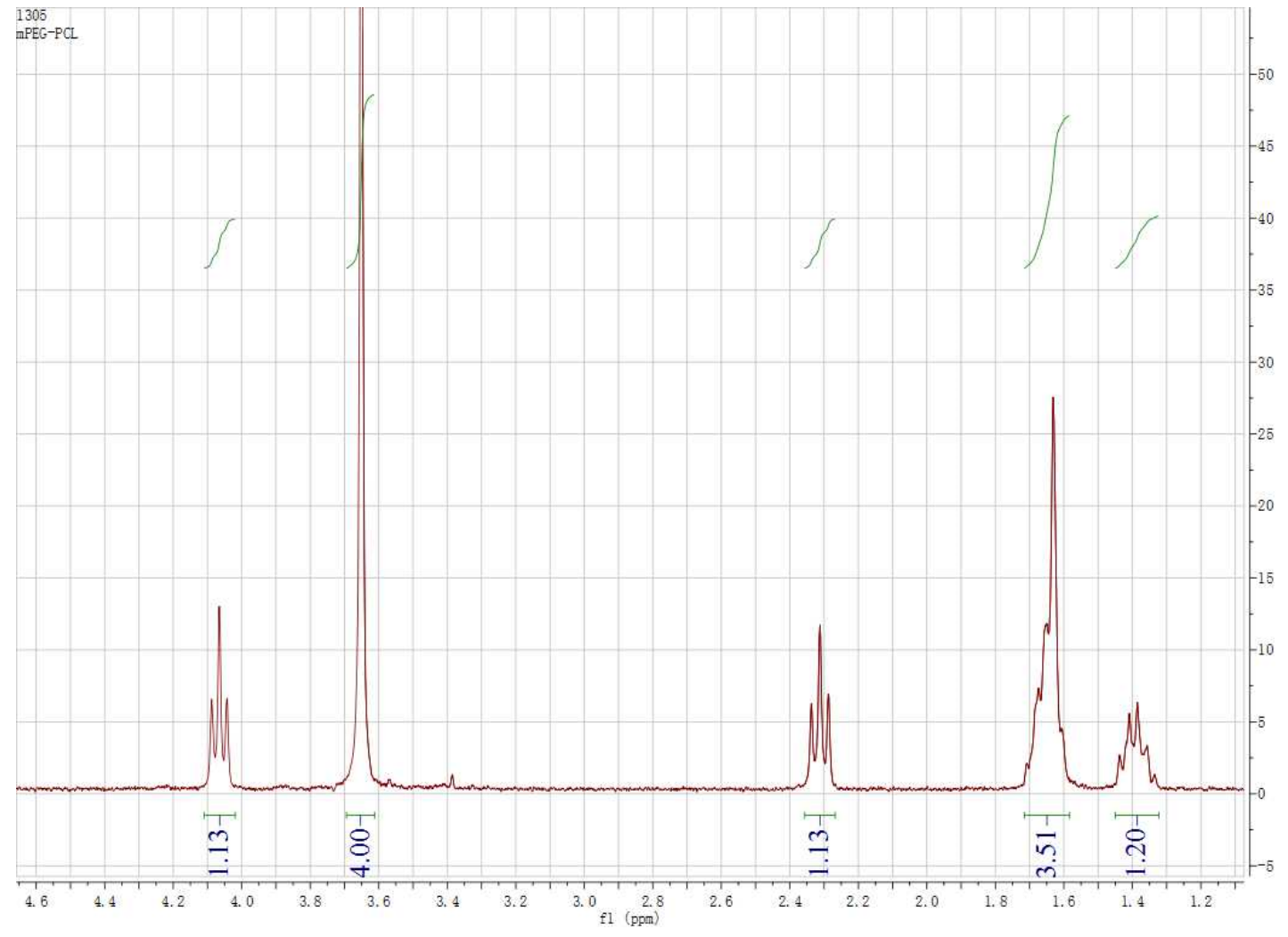

Figure S5. ${ }^{1} \mathrm{H}$ NMR spectra of PCL-PEG in $\mathrm{CDCl}_{3}$. 

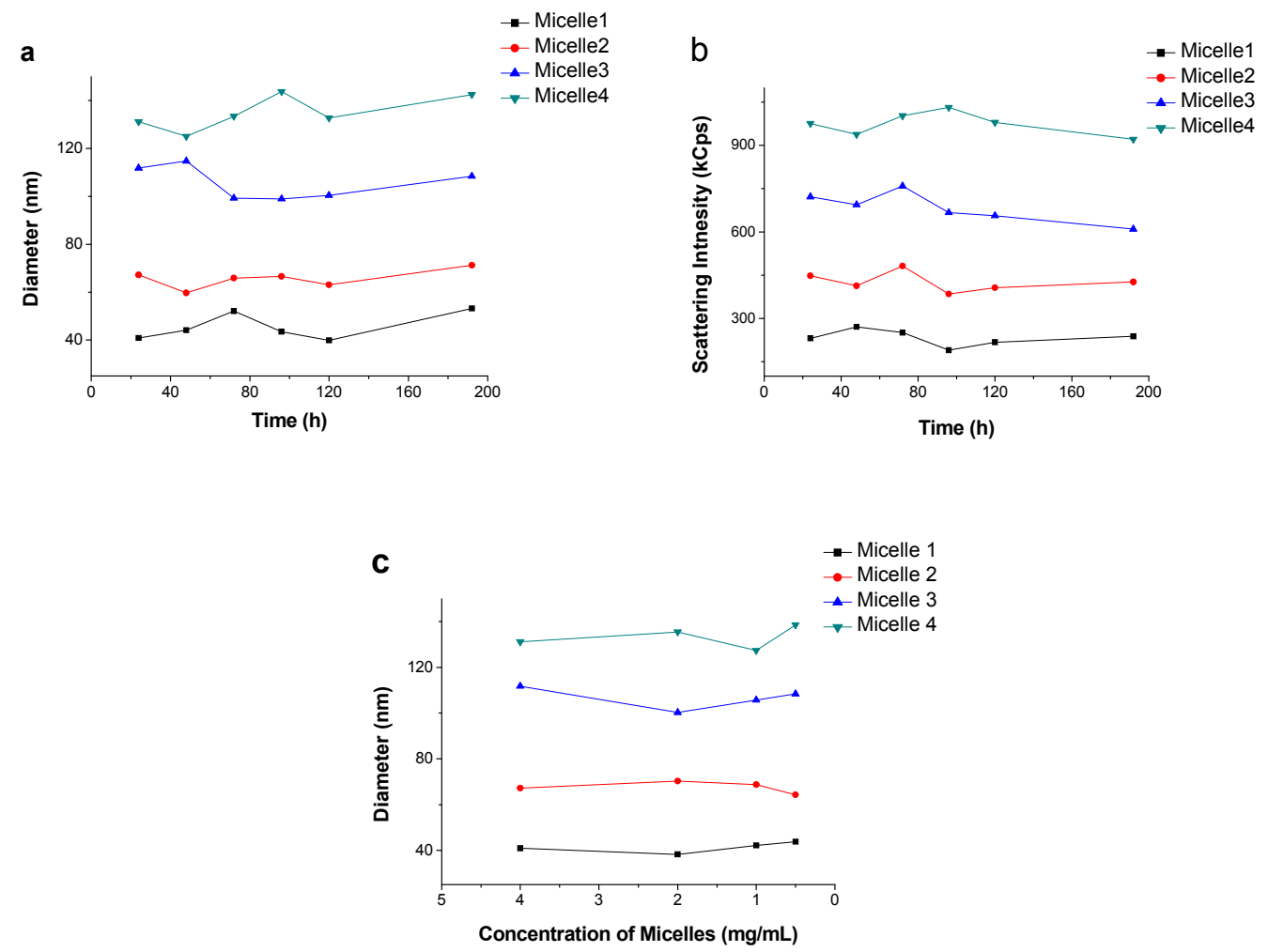

Figure S6. Micelle diameter (a) and scattering intensity (b) of the $4 \mathrm{mg} / \mathrm{mL}$ suspensions of Micelle 1, Micelle 2, Micelle 3 and Micelle 4 in PBS $(\mathrm{pH}=7.4,0.01 \mathrm{mM})$ determined by DLS. (c) Micelle diameter of the suspensions of Micelle 1, Micelle 2, Micelle 3 and Micelle 4 at different concentrations in $\mathrm{PBS}(\mathrm{pH}=7.4,0.01 \mathrm{mM})$. 


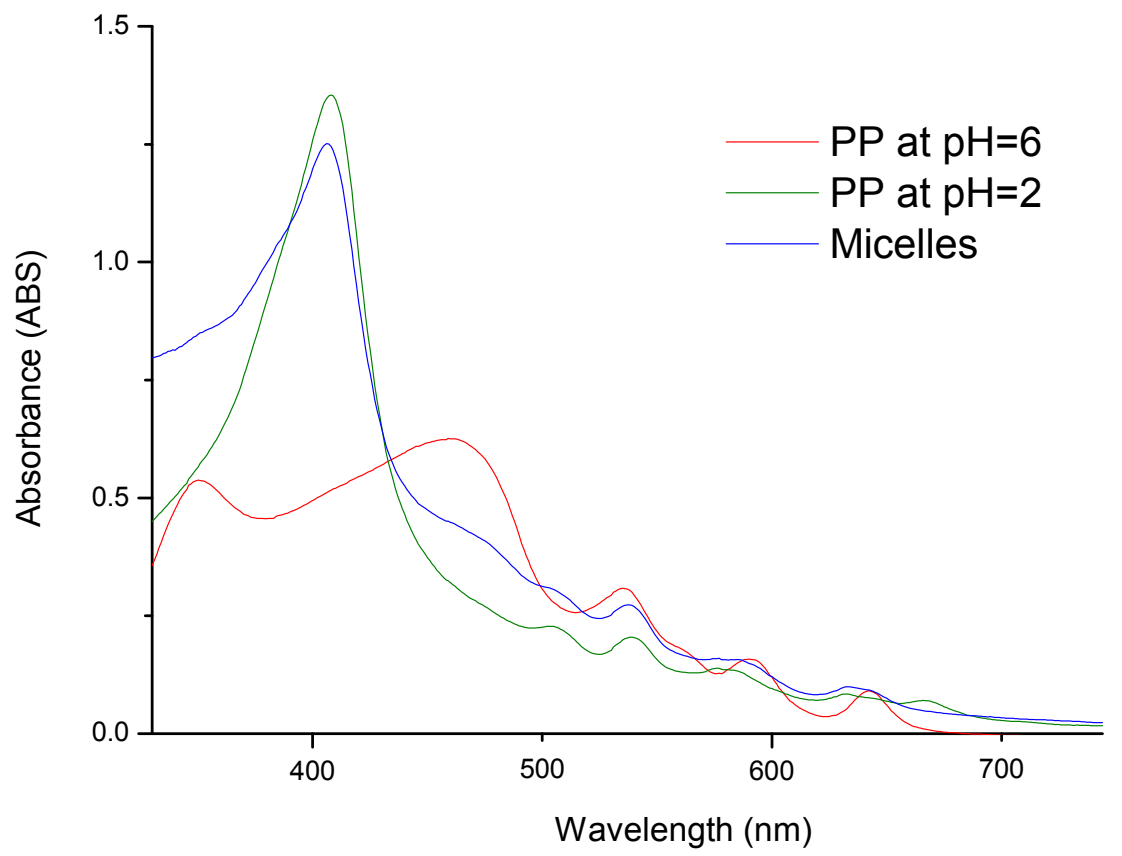

Figure S7. UV-vis spectra of $5 \mathrm{mg} / \mathrm{mL}$ PP-PCL-PEG micelle suspension in deionized water and $0.01 \mathrm{mg} / \mathrm{mL}$ PP aqueous solutions at $\mathrm{pH} 2$ and 6 . 


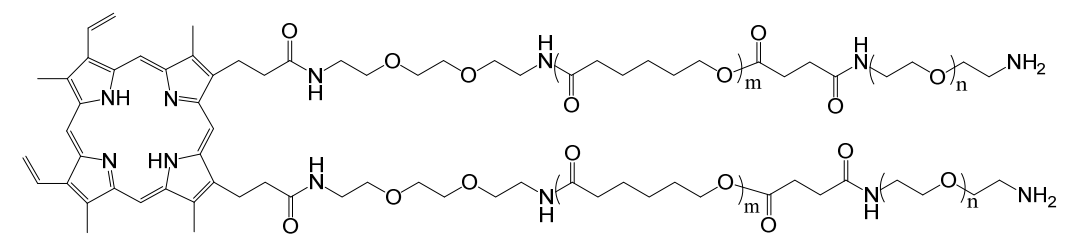

PP-PCL-PEG

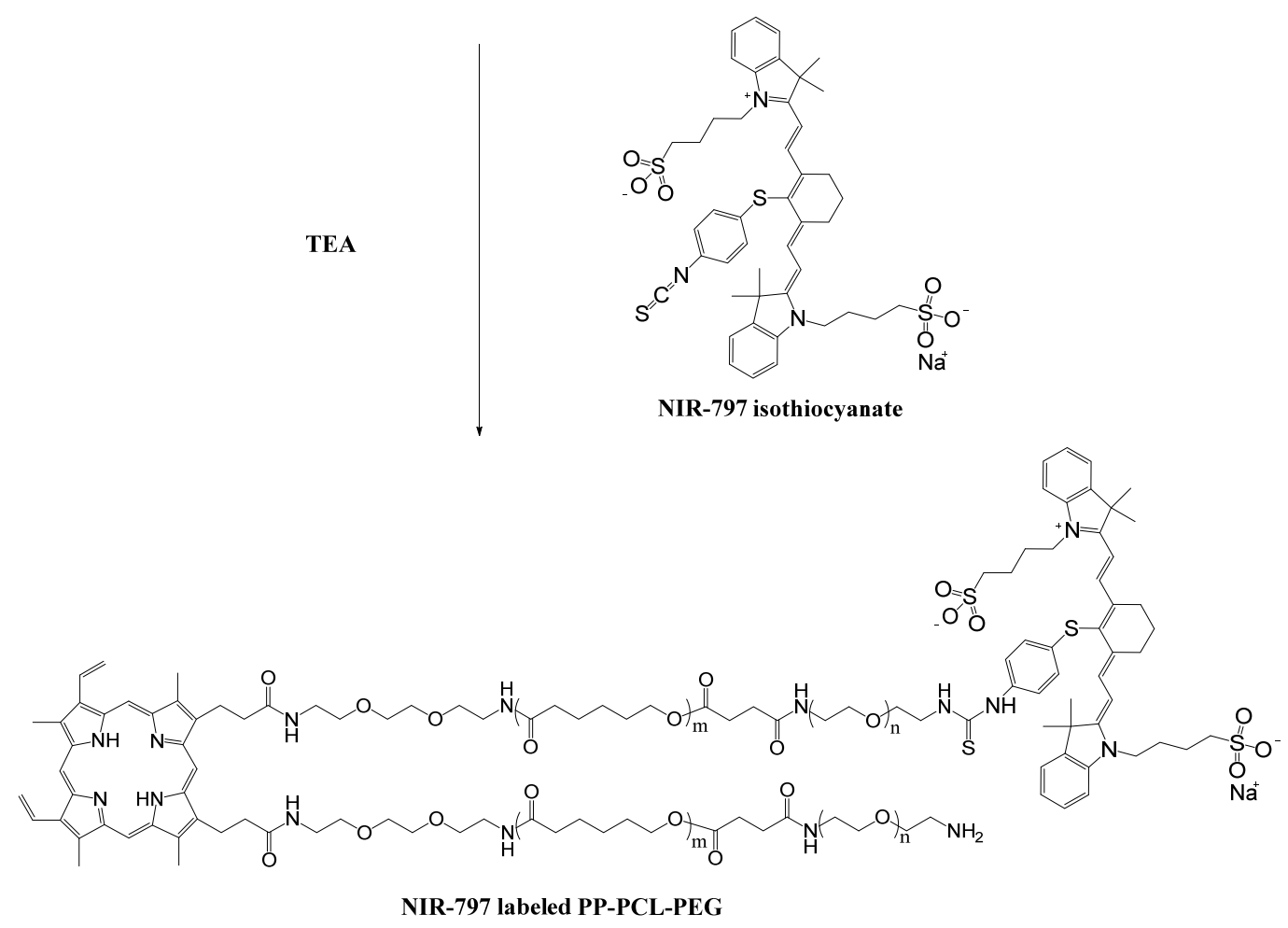

Scheme S1. Synthesis of NIR-797-labeled PP-PCL-PEG 